\title{
PENGARUH MODEL STAD TERHADAP HASI L BELAJAR SISWA DALAM PKN DI KELAS IV SDN O3 SIMPANG HARU
}

\author{
Oleh: \\ Dara Marta Dilla \\ daramartadiila19@gmail.com
}

\begin{abstract}
Abstrak
Penelitian bertujuan untuk membuktikan pengaruh model (STAD) terhadap hasil belajar PKn kelas IV. Jenis penelitian adalah quasy experiment dalam bentuk nonequivalent control group design. Populasi penelitian ini adalah seluruh siswa kelas IV SDN 03 Simpang Haru. Sampel dalam penelitian ini adalah kelas $\mathrm{IV}_{\mathrm{A}}$ dan kelas $\mathrm{IV}_{\mathrm{B}}$. Hasil penelitian menunjukkan bahwa rata-rata nilai postest pada kelompok kontrol yaitu 82,83dan kelompok eksperimen 87,50 serta nilai thitung sebesar -3.021 dengan P-Value sebesar 0.004 , jadi, nilai P-Value yang diperoleh lebih kecil dari $\alpha$ $=0.05$, maka $\mathrm{H}_{0}$ ditolak
\end{abstract}

Kata kunci : model STAD, hasil belajar.

\begin{abstract}
The study alms to prove the effect of STAD model on the learning outcomes of civics class IV. The type of research is quasy experiment un the form of nonequivalent control group design. The population of this reseach is all students of grade IV SDN 03 Simpang Haru. The sample in this reseach is class $I_{\mathrm{A}}$ and class $\mathrm{IV}_{\mathrm{B}}$. The results of this study indicate that the avarege postest score in the control group is 82.83 and the tcount of -3.021 with P-Value of 0.004 , so the of P-value
\end{abstract}

Keywords : STAD model, learning outcomes 


\section{PENDAHULUAN}

Model STAD ini, meskipun siswa belajar dalam tim, mereka tidak boleh saling bantu dalam mengerjakan tes atau kuis. Tiap siswa harus paham dengan materi yang sedang dipelajarinya.Tanggung jawab individual seperti ini memotivasi siswa untuk memberi penjelasan dengan baik satu sama lain, karena satu-satunya cara bagi tim untuk berhasil adalah dengan membuat semua anggota tim menguasai informasi atau kemampuan yang diajarkan. Karena skor tim didasarkan pada kemajuan yang dibuat anggotanya.

Menurut Slavin (2009:143) "STAD merupakan salah satu metode pembelajaran cooperative yang paling sederhana, dan merupakan model yang paling baik untuk permulaan bagi para guru yang baru menggunakan pendekatan cooperative”. Lebih lanjut Slavin (dalam Asma, 2012:58) mengemukakan bahwa:

Pembelajaran cooperative dengan model STAD, siswa ditempatkan dalam kelompok belajar beranggotakan empat atau lima orang siswa yang merupakan campuran dari kemampuan akademik yang berbeda, sehingga dalam setiap kelompok terdapat siswa yang berprestasi tinggi, sedang dan rendah atau variasi jenis kelamin, kelompok ras kelompok ras dan etnis atau kelompok sosial lainnya. Guru terlebih dahulu menyajikan materi baru dalam kelas, kemudian anggota team mempelajari dan berlatih untuk materi tersebut dalam kelompok mereka yang biasanya bekerja berpasangan. Mereka melengkapi lembar kerja, bertanya satu sama lain, membahas masalah dan mengerjakan latihan. Tugas-tugas mereka harus dikuasai oleh setiap anggota kelompok. Pada akhirnya guru memberikan kuis yang harus dikerjakan siswa secara individu.

Model STAD pada pembelajaran Pendidikan Kewarganegaraan (PKn) mengemukakan langkah-langkah model STAD menurut Sharan (dalam Taniredja, 2012:66), yaitu:

(1) Buatlah salinan lembar rekapitulasi kelompok, (2) Merangking siswa, dari yang paling pintar ke paling kurang pintar, (3) Tentukan jumlah anggota kelompok, jika memungkinkan tiap-tiap kelompok harus memilih empat anggota, (4) Masukkan siswa kedalam kelompok secara berimbang, (5) Sebarkan lembar rekapitulasi siswa, (6) Tentukan nilai dasar.

Sedangkan menurut Slavin langkah-langkah STAD Menurut Slavin (2009:143146) yakni: (1) Presentasi kelas, (2) Tim, (3) Kuis, (4) Skor kemajuan individual, (5) Rekognisi tim. 
Selain memiliki langkah-langkah, model STAD juga memiliki beberapa keunggulan. Slavin (2009:12) menyatakan bahwa keunggulan model STAD, antara lain: Gagasan utama dari STAD adalah untuk memotivasi siswa supaya dapat saling mendukung dan membantu satu sama lain dalam meningkatkan daya pikir dan menguasai kemampuan yang diajarkan oleh guru. Jika para siswa ingin agar timnya mendapatkan penghargaan tim, mereka harus membantu teman satu timnya untuk mempelajari materinya.

Kurniasih (2015) mengemukakan keunggulan STAD antara lain:

(1) Karena dalam kelompok siswa dituntut untuk aktif sehingga siswa dengan sendirinya akan percaya diri dan meningkat kecakapan individunya, (2) interaksi sosial terbangun dalam kelompok siswa belajar dalam bersosialisasi dengan lingkungannya (kelompoknya), (3) dengan adanya kelompok siswa diajarkan untuk membangun komitmen dalam mengembangkan kelompoknya, (4) mengajarkan menghargai orang lain dan saling percaya, (5) dalam kelompok siswa diajarkan untuk saling mengerti dengan materi yang ada sehingga siswa salin memberitahu dan mengurangi sifat kompetitif.

Berdasarkan hasil observasi yang dilakukan di kelas IVA dan IVB SDN 03 Simpang Haru pada tanggal 12-14 Mei 2017 menunjukkan bahwa guru belum menerapkan model pembelajaran kooperatif tipe STAD. Dampak dari tidak digunakannya model STAD adalah siswa menjadi pasif dalam pembelajaran, sehingga pembelajaran menjadi tidak bermakna dan hasil belajar siswa pada pembelajaran PKn rendah. Berdasarkan hasil ujian MID semester 1 tahun ajaran 2016/2017 pada mata pelajaran PKn kelas IVA dan IVB menunjukkan bahwa kelas IVA dengan jumlah 24 siswa yang mencapai KKM adalah 10 orang (42\%) dan kelas IVB dengan jumlah 24 siswa yang mencapai KKM adalah 11 siswa (46\%). Hal tersebut menunjukkan bahwa sebagian besar nilai siswa belum mencapai KKM yang ditetapkan.

Berdasarkan permasalahan di atas maka peneliti tertarik untuk melakukan penelitian dengan judul "Pengaruh Model "Pengaruh Model STAD terhadap Hasil Belajar Siswa dalam Pembelajaran Pendidikan Kewarganegaraan di kelas IV SDN 03 Simpang Haru".

Tujuan penelitian ini adalah "Melihat pengaruh yang signifikan model Pengaruh Model "Pengaruh Model STAD terhadap Hasil Belajar Siswa dalam Pembelajaran Pendidikan Kewarganegaraan di kelas IV SDN 03 Simpang Haru”. 


\section{METODE PENELITIAN}

Rancangan penelitian ini menggunakan metode penelitian eksperimen. Jenis penelitian yang digunakan yaitu eksperimen semu (quasi eksperimental design). Ali (2012:101) menyatakan "Eksperimen semu atau bukan eksperimen sejati digunakan apabila pelaksanaan studi itu ada kendala-kendala pemenuhan kriteria, yaitu terkait pemilihan subyek sampel secara random dan penugasan subyek secara random sehingga tidak mempresentasikan kondisi sebenarnya atau kuasi eksperimen". Desain ini dipilih karena tidak memungkinkan untuk mengontrol variable penelitian secara penuh.

Rancangan penelitian ini menggunakan dua kelas yaitu kelas eksperimen dan kelas kontrol. Kelas eksperimen adalah kelas yang sengaja diberi perlakuan model STAD, sedangkan kelas kontrol menggunakan non STAD. Kelas eksperimen dan kelas kontrol akan diberi perlakuan yang berbeda dengan materi yang sama. Pada setiap akhir pembelajaran diberi tes akhir. Tujuannya untuk mengetahui ada tidaknya pengaruh model STAD terhadap hasil belajar PKn siswa dari kedua kelas sampel setelah diberi perlakuan yang berbeda, yaitu dengan cara mem bandingkan hasil belajar kelas eksperimen dengan kelas kontrol.

Menurut Sugiyono (2011:80) "Populasi adalah wilayah generalisasi yang terdiri atas obyek/subyek yang mempunyai kualitas dan karakterisitik tertentu yang ditetapkan oleh peneliti untuk dipelajari dan kemudian ditarik kesimpulannya". Populasi pada penelitian ini adalah seluruh siswa di kelas IV SDN 03 Simpang Haru.

Ali (2010:257) menyatakan bahwa "Sampel adalah bagian yang mewakili populasi, yang diambil dengan menggunakan teknik-teknik tertentu”. Teknik penarikan sampel yang digunakan dalam rancangan penelitian ini adalah purposive sampling. Menurut Karunia dan Mukhmmad (2015:137) teknik purposive sampling adalah teknik penentuan sampel dengan pertimbangan tertentu.

Sampel yang dipilih dalam rancangan penelitian ini adalah kelas IVA dan IVB. Dasar pertimbangan pemilihan kelas IVA dan IVB sebagai sampel adalah (1) Berdasarkan uji normalitas, diperoleh bahwa data kelas IVA dan IVB 
berdistribusi normal dan (2) Berdasarkan uji homogenitas, diperoleh bahwa data kelas IVA dan IVB homogen. Pemilihan kelas kontrol dan kelas eksperimen dilakukan secara undian. Berdasarkan undian kelas IVA sebagai kelas kontrol, IVB sebagai kelas eksperimen.

Instrumen yang akan digunakan dalam penelitian ini adalah tes hasil belajar. Lestari dan Yudhanegara (2015:164) mengemukkan bahwa "tes adalah alat yang digunakan dalam rangka pengukuran dan penilaian, biasanya berupa jumlah pertanyaan/soal yang diberikan untuk dijawab oleh subjek yang diteliti”. Tes yang digunakan dalam penelitian ini adalah tes tertulis dalam bentuk pilihan ganda dengan kompetensi dasar 1.1 Mengenal lembaga-lembaga dalam susunan pemerintahan desa dan pemerintah kecamatan.

Tes ini terdiri dari satu jenis, yaitu posttest. Posttest bertujuan untuk mengetahui perkembangan hasil belajar. yang digunakan berupa posttest dalam bentuk pilihan ganda yang berjumlah 35 soal. Suharsimi (2009:121) menyebutkan bahwa ranah kognitif yang cocok diterapkan disekolah dasar adalah ingatan, pemahaman, dan aplikasi (penerapan). Oleh karena itu dalam rancangan penelitian ini penyusunan soal posttest hanya mengambil 6 aspek saja yaitu : $\mathrm{C} 1, \mathrm{C} 2$, dan C3, C4, C5, dan C6.

Dalam rancangan penelitian ini, uji hipotesis yang digunakan adalah uji-t. menurut Lestari dan Yudhanegara (2015:256-260), Uji-t digunakan untuk menguji hipotesis dalam penelitian yang melibatkan satu perlakukan atau satu pengukuran yang menggunakan rata-rata sebagai parameter atau pada sampel yang berukuran kecil $n \leq 30$ atau jika simpangan baku populasi tidak diketahui. Uji-t dapat digunakan jika jenis data yang akan dianalisis berskala interval atau rasio dan data berdistribusi normal.

Uji t dilakukan dengan bantuan SPSS v 17 dengan mengikuti langkahlangkah menurut Lestari dan Yudhanegara (2015:256-260). Setelah nilai t-test diketahui, selanjutnya melakukan intepretasi data dengan cara membandingkan nilai thitung dengan nilai $t_{\text {table }}$ pada taraf signifikasi 5\%. Jika $-t_{\text {hitung }}<-t_{\text {tabel }}$ atau $t_{\text {hitung }}$ > tabel maka dapat disimpulkan bahwa pendekatan yang diberikan berpengaruh terhadap hasil belajar peserta didik dan bila $t_{\text {hitung }}>-\mathrm{t}_{\text {tabel }}$ atau $\mathrm{t}_{\text {hitung }}<\mathrm{t}$ tabel maka 
diketahui bahwa cara yang diberikan peneliti tidak berpengaruh terhadap hasil belajar peserta didik atau dapat menggunakan kesimpulan dengan kriteria sebagai berikut:

H0 : Tidak Adanya pengaruh model STAD terhadap hasil belajar siswa pada pembelajaran PKn di kelas IV SDN 03 Simpang Haru.

H1 : Adanya pengaruh model STAD terhadap hasil belajar siswa pada pembelajaran PKn di kelas IV SDN 03 Simpang Haru.

\section{HASIL PENELITIAN}

\section{A. Deskripsi Data Hasil Penelitian}

Penelitian ini dilakukan di kelas IV SDN 03 Simpang Haru Kota Padang pada semester I tahun ajaran 2017/2018. Sebelum dilakukan penelitian, peneliti melakukan uji coba soal. Dari 35 butir soal yang diujikan terdapat 10 butir soal yang tidak valid sehingga didapat 25 butir soal yang valid. Selanjutnya, penelitian ini dilakukan sebanyak 2 kali pertemuan, 1 kali pertemuan pada kelas kontrol dan 1 kali pertemuan di kelas eksperimen. Populasi dalam penelitian ini adalah seluruh siswa kelas IV SDN 03 Simpang Haru sebanyak 48 orang siswa. Sampel dalam penelitian ini adalah Kelas IV SDN 03 Simpang Haru berjumlah 48 siswa yang terdiri dari 24 siswa kelas kontrol dan 24 siswa kelas eksperimen. Kedua kelas diberi perlakuan yang berbeda, untuk kelas eksperimen diajarkan menggunakan Model STAD sedangkan kelas kontrol menggunakan model konvensional. Setelah diberikan perlakuan siswa pada kedua kelas tersebut diberikan postest berupa soal.

1. Data Hasil Tes di Kelas Kontrol dan Eksperimen

a. Data Hasil Pretest dan Postest di Kelas Kontrol dan Eksperimen

1) Nilai Pretest di kelas Kontrol dan Eksperimen

Nilai pretest diberikan kepada siswa kelompok kontrol dan eksperimen sebelum diberikan pembelajaran. Nilai pretest ini digunakan untuk mengetahui kemampuan awal siswa tentang mengenal lembagalembaga dalam susunan pemerintahan desa dan pemerintahan kecamatan. dapat dilihat pada tabel dibawah ini. 


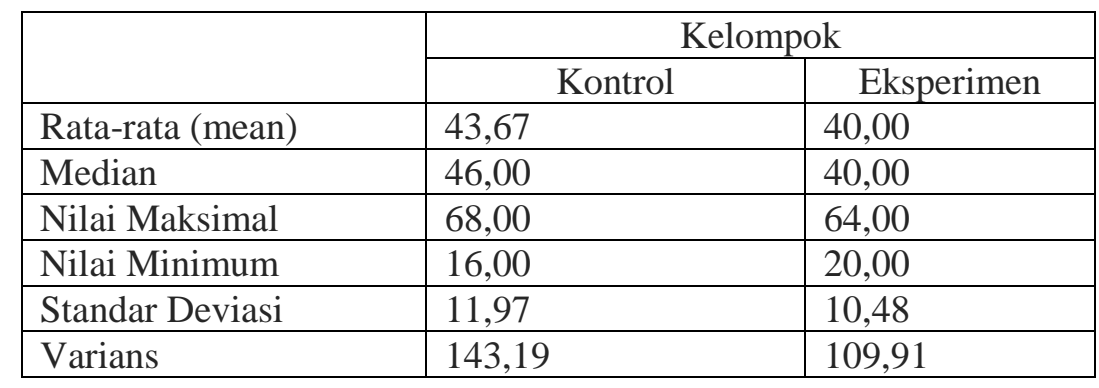

2) Nilai postest di kelas Kontrol dan Eksperimen

Nilai posttest didapat melalui tes yang diberikan pada siswa kelompok kontrol dan kelompok eksperimen setelah perlakuan pembelajaran selesai. Nilai postest ini digunakan untuk mengetahui kemapuan akhir siswa pada materi pembelajaran menunjukkan mengenal lembaga-lembaga dalam susunan pemerintahan desa dan pemerintah kecamatan yang digunakan untuk menguji hipotesis. Hasil dari nilai postest dapat dilihat pada tabel di bawah ini:

\begin{tabular}{|l|c|c|}
\hline \multirow{2}{*}{\multicolumn{1}{|c|}{ Uraian }} & \multicolumn{2}{c|}{ Kelompok } \\
\cline { 2 - 3 } & Kontrol & Eksperimen \\
\hline Rata-rata (mean) & 82,83 & 87,50 \\
\hline Median & 84,00 & 88,00 \\
\hline Nilai Maksimal & 96,00 & 100,00 \\
\hline Nilai Minimum & 68,00 & 72,00 \\
\hline Standar Deviasi & 7,78 & 6,91 \\
\hline Varians & 60,49 & 47,74 \\
\hline
\end{tabular}

\section{B. Uji Persyaratan Analisis}

Sebelum melakukan uji t untuk hipotesis maka perlu dilakukan uj prasyarat yaitu uji normalitas dan uji homogenitas.

1. Uji Normalitas

Pada penelitian ini,uji normalitas dilakukan dengan bantuan SPSS v.16. Uji normalitas ini ditentukan dengan menggunakan Shapiro Wilk seperti yang telah dijelaskan pada Bab III. Taraf signifikansi uji normalitas $(\alpha)$ sebesar 5\% (0.05). Hipotesis uji normalitas pada penelitian ini adalah:

$\mathrm{H}_{0} \quad$ : Data berdistribusi normal

$\mathrm{H}_{1} \quad$ : Data tidak berdistibusi normal

Hasil data postest, uji normalitas kelas eksperimen dapat dilihat pada tabel di bawah ini sebagai berikut. 
Tabel Uji Normalitas Postest di Kelas Eksperimen

\section{Tests of Normality}

\begin{tabular}{|l|l|l|l|l|l|l|}
\hline \multirow{2}{*}{} & \multicolumn{6}{|l|}{ Kolmogorov-Smirnov } \\
& Statistic & Df & Shapiro-Wilk & Statistic & df & Sig. \\
\hline VAR00001 & 159 & 24 & .118 & .963 & 24 & .495 \\
\hline
\end{tabular}

a. Lilliefors Significance Correction

Pada tabel 4.11, diperoleh P-Value yang diperoleh sebesar 0.115 . Karena nilai $\mathrm{P}-$ Value $>\alpha$, maka $\mathrm{H}_{0}$ diterima (tidak cukup bukti/data untuk menolak $\mathrm{H}_{0}$ ). Dengan demikian, dapat disimpulkan bahwa pada taraf kepercayaan 95\%, data postest di kelas eksperimen berdistribusi normal.

Selanjtnya hasil data postest, uji normalitas kelas kontrol dapat dilihat pada tabel di bawah ini sebagai berikut.

Tabel Uji Normalitas Postest di Kelas Kontrol

\section{Tests of Normality}

\begin{tabular}{|l|l|r|r|r|r|r|r|}
\hline & \multicolumn{6}{|c|}{$\begin{array}{l}\text { Kolmogoro } \\
\text { V-Smirnov }\end{array}$} & \multicolumn{6}{|c|}{ Shapiro-Wilk } \\
\cline { 2 - 8 } & \multicolumn{2}{|c|}{ Statistic } & Df & Sig. & Statistic & Df & Sig. \\
\hline VAR00001 & & .143 & 24 & $.200^{*}$ & .943 & 24 & .191 \\
\hline
\end{tabular}

a. Lilliefors Significance Correction

*. This is a lower bound of the true significance.

Pada tabel 4.8, diperoleh P-Value yang diperoleh sebesar 0.191. Karena nilai P-Value $>\alpha$, maka $\mathrm{H}_{0}$ diterima (tidak cukup bukti/data untuk menolak $\mathrm{H}_{0}$ ). Dengan demikian, dapat disimpulkan bahwa pada taraf kepercayaan 95\%, data postest di kelas kontrol berdistribusi normal.

\section{Uji Homogenitas Variansi}

Berdasarkan hasil data postest, uji homogenitas kelas kontrol dan kelas eksperimen dapat dilihat pada tabel 4.14 sebagai berikut.

Tabel Uji Homogenitas Postest di Kelas Kontrol dan Eksperimen 


\section{Test of Homogeneity of Variances}

\begin{tabular}{|c|c|c|c|}
\hline Levene Statistic & df1 & df2 & Sig. \\
\hline .179 & 1 & 46 & .675 \\
\hline
\end{tabular}

Pada tabel 4.14, diperoleh P-Value yang diperoleh sebesar 0.675. Karena nilai P-Value $>\alpha$, maka $\mathrm{H}_{0}$ diterima (tidak cukup bukti/data untuk menolak $\mathrm{H}_{0}$ ). Dengan demikian, dapat disimpulkan bahwa pada taraf kepercayaan 95\%, data postest kedua varians homogen.

\section{Pengujian Hipotesis}

Setelah pengujian prasyarat analisis terpenuhi, selanjutnya dilakukan uji hipotesis dengan menggunakan uji $t$ untuk dua sampel independen.Uji $t$ untuk dua sampel independen dilakukan berdasarkan data hasil postest di kelas kontrol dan eksperimen. Uji t untuk dua sampel independen dilakukan dengan bantuan SPSS v.17. Taraf signifikansi uji t $(\alpha)$ sebesar 5\% (0.05). Hipotesis uji t pada penelitian ini adalah:

H0 : Tidak adanya pengaruh model STAD terhadap hasil belajar siswa pada pembelajaran PKn di kelas IV SDN 03 Simpang Haru.

H1 : Adanya pengaruh model STAD terhadap hasil belajar siswa pada pembelajaran PKn di kelas IV SDN 03 Simpang Haru.

Uji Hipotesis Berdasarkan Data Postest Kelas Kontrol dan Eksperimen. Berdasarkan hasil data postest di kelas kontrol dan eksperimen, maka hasil uji t dapat dilihat pada tabel di bawah ini

Tabel. Uji t untuk Dua Sampel Independen berdasarkan Postest di Kelas Kontrol dan Eksperimen. 
Independent Samples Test

\begin{tabular}{|c|c|c|c|c|c|c|c|c|c|}
\hline & \multicolumn{2}{|c|}{$\begin{array}{l}\text { Levene's Test } \\
\text { for Equality } \\
\text { of Variances }\end{array}$} & \multicolumn{7}{|c|}{ t-test for Equality of Means } \\
\hline & \multirow[b]{2}{*}{$\mathrm{F}$} & \multirow[b]{2}{*}{ Sig. } & \multirow[b]{2}{*}{$\mathrm{T}$} & \multirow[b]{2}{*}{ Df } & \multirow[b]{2}{*}{$\begin{array}{l}\text { Sig. (2- } \\
\text { tailed) }\end{array}$} & \multirow[b]{2}{*}{$\begin{array}{c}\text { Mean } \\
\text { Difference }\end{array}$} & \multirow[b]{2}{*}{$\begin{array}{l}\text { Std. Error } \\
\text { Difference }\end{array}$} & \multicolumn{2}{|c|}{$\begin{array}{c}95 \% \\
\text { Confidence } \\
\text { Interval of } \\
\text { the } \\
\text { Difference }\end{array}$} \\
\hline & & & & & & & & Lower & Upper \\
\hline $\begin{array}{l}\text { VAR Equal } \\
0000 \text { variances } \\
1 \quad \text { assumed }\end{array}$ & .179 & .675 & -3.02 & 46 & .004 & -6.18 & 2.04 & -10.30 & -2.06 \\
\hline $\begin{array}{l}\text { Equal } \\
\text { variances } \\
\text { not assumed }\end{array}$ & & & -3.00 & 43.76 & .004 & -6.18 & 2.05 & $\mid-10.32$ & -2.03 \\
\hline
\end{tabular}

Pada tabel di atas, diperoleh nilai P-Value untuk Levene's test sebesar

0.675 , karena nilai tersebut lebih besar dari $\alpha=0.05$, maka varians kedua data homogen. Nilai yang ada pada kolom t merupakan thitung yang diperoleh dari hasil perhitungan. Nilai t pada baris pertama, yaitu -3.021 merupakan nilai hasil uji t jika varians kedua data homogen (equal varians assumed), sementara nilai t pada baris kedua, yaitu -3.007 merupakan nilai hasil uji-t yang digunakan jika varians kedua data tidak homogen (equal varians not assumed). Karena hasil uji levene's test menyatakan kedua varians homogen, maka nilai thitung yang digunakan adalah yang berdasarkan uji t, yaitu sebesar -3.021 dengan P-Value sebesar 0.004.

Nilai P-Value yang diperoleh lebih kecil dari $\alpha=0.05$, maka $\mathrm{H}_{0}$ ditolak. Artinya pada taraf kepercayaan $95 \%$ berdasarkan data postest di kelas kontrol dan eksperimen dapat disimpulkan bahwa terdapat pengaruh model STAD terhadap hasil belajar siswa pada pembelajaran PKn di kelas IV SDN 03 Simpang Haru.

\section{PEMBAHASAN}

Model kooperatif tipe $S T A D$ adalah suatu model kooperatif yang paling sederhana. Dimana dalam pembelajaran kooperatif tipe $S T A D$ siswa bekerja sama 
dalam kelompok-kelompok kecil yang heterogen beranggotakan 4-5 orang yang masing-masing anggota memiliki kemampuan akademik yang berbeda.

Penggunaan model STAD dapat juga digunakan mata pelajaran PKn bertujuan agar siswa dapat berfikir secara kritis, rasional serta dapat berkembang secara positif dalam kegiatan berbangsa dan bernegara agar mencapai hasil belajar yang maksimal dalam pembelajaran PKn, model yang bagus digunakan adalah model STAD dimana model ini bertujuan untuk memotivasi siswa supaya dapat saling mendukung dan membantu satu sama lain.

Berdasarkan hasil uji coba soal, dari 35 butir soal yang peneliti buat. Setelah dilakukan uji coba, terdapat 25 butir soal yang valid dan 10 butir soal yang tidak valid sesuai dengan pendapat Lestari dan Yudhanegara (2015:198-227) menyebutkan bahwa uji validitas, reliabilitas, daya pembeda dan indeks kesukaran dapat menggunakan software anatest. Oleh karena itu, dalam rancangan penelitian ini, uji validitas, reliabilitas, daya pembeda dan indeks kesukaran menggunakan software anatest v4 dengan mengikuti langkah-langkah menurut Lestari dan Yudhanegara.

Hasil penelitian mengenai uji normalitas pretes dan postest dikelas kontrol diperoleh hasil $P$-Value untuk pretes sebesar 0,792 dengan $<5 \%$ menunjukkan $\mathrm{H}_{0}$ diterima, dan $P$-Value postest 0,191 dengan $<5 \%$ menunjukkan $\mathrm{H}_{0}$ diterima dan data berdistribusi normal. Hasil penelitian mengenai uji normalitas pretes dan postest di kelas eksperimen di peroleh hasil P-Value untuk pretes sebesar 0,827 dengan $<5 \%$ menunjukkan $\mathrm{H}_{0}$ diterima dan data berdistribusi normal, dan $P$-Value postest diperoleh sebesar 0,115 dengan $<5 \%$ menunjukkan $\mathrm{H}_{0}$ diterima dan data berdistribusi normal.

Hasil penelitian mengenai uji homogonitas pada pretes menunjukkan $P$ Value diperoleh sebesar 0,381. P-Value $>\alpha$, maka $\mathrm{H}_{0}$ diterima dan dapat disimpulkan bahwa data pretest kedua varians dinyatakan homogen. Hasil penelitian mengenai uji homogonitas pada posts menunjukkan $P$-Value di peroleh sebesar 0,609 dengan < 5\%. P-Value > $\alpha$, maka $\mathrm{H}_{0}$ diterima dan dapat disimpulkan bahwa data postes kedua varians dimyatakan homogen. 
Hasil uji hipotesis menggunakan uji t dilakukan dengan bantuan SPSS v.17 dengan taraf signifikansi uji t $(<)$ sebesar 5\% $(0,05)$ di peroleh nilai $P$-Value sebesar 0,675 dikarenakan nilai $P$-Value besar dari $<(\mathrm{P}-$ Value $>)$, dengan $<=5 \%$, maka varians kedua data homogen.

Nilai t pada baris pertama yaitu $-3,021$ jika varians kedua yaitu $-3,007$ jika varians kedua data tidak homogen, berdasarkan uji Levene's test dapat dinyatakan kedua varians homogen, maka nilai thitung yang digunakan adalah yang berdasarkan uji t, yaitu sebesar -3,021 dengan $P$-Value sebesar 0,004. Nilai $P$ Value lebih kecil dari $<=0,05$ ( $P$-Value $<)$, maka $\mathrm{H}_{0}$ ditolak. Berdasarkan hasil perhitungan tersebut, dapat disimpulkan terdapat pengaruh model STAD terhadap hasil belajar siswa dalam pembelajaran pendidikan kewarganegaraan di kelas IV SDN 03 Simpang Haru.

\section{SIMPULAN DAN SARAN}

Berdasarkan hasil penelitian diperoleh rata-rata nilai postest pada kelompok kontrol yaitu 82,83 dan kelompok eksperimen 87,50 serta nilai thitung sebesar -3.021 dengan P-Value sebesar 0.004. Jadi, nilai P-Value yang diperoleh lebih kecil dari $\alpha=0.05$, maka $\mathrm{H}_{0}$ ditolak. Artinya pada taraf kepercayaan $95 \%$ berdasarkan data posstest di kelas kontrol dan eksperimen dapat disimpulkan bahwa adanya pengaruh model STAD terhadap hasil belajar siswa pada pembelajaran PKn di kelas IV SDN 03 Simpang Haru

Berdasarkan simpulan yang telah diuraikan di atas, dapat dikemukakan beberapa saran sebagai berikut: 1)bagi guru agar dapat menggunakan model STAD dalam proses pembelajaran PKn di SD, karena penerapan model STAD dapat meningkatkan hasil belajar siswa,2)Bagi kepala sekolah sebagai informasi dalam pembina personil guru dalam memberikan sumbangan yang positif untuk perbaikan proses pembalajaran,3) Penelitian ini hanya meneliti hasil belajar siswa menggunakan model STAD dan pembelajaran konvensional dilakukan guru. Untuk itu, disarankan pada peneliti selanjutnya untuk meneliti aspek-aspek lainnya,4) Bagi peneliti yang lain berminat diharapkan mengadakan peneleitian lanjutan dengan dapat mengantisipasi kendala-kendala yang terjadi. 


\section{DAFTAR RUJUKAN}

Asma, Nur. 2012. Model Pembelajaran Kooperatif. Padang: UNP Press.

Ali, Mohammad. 2010. Metodologi dan Aplikasi Riset Pendidikan. Bandung: Cendikia Utama

Karunia dan Mokhammad. 2015. Penelitian Pendidikan Matematika. Bandung : PT Refika Aditama.

Kurniasih, Imas dan Sani, Berlin. 2014. Sukses Mengimplementasikan Kurikulum 2013 Memahami Berbagai Aspek dalam Kurikulum 2013. Jakarta: Kata Pena.

Sugiyono. 2011. Metode Penelitian Kuantitatif Kualitatif Dan R\&D. Bandung : Alfabeta.

Slavin, Robert E. 2009. Cooperatif Learning Teori, Riset, dan Praktik. Bandung: Nusa Media.

Taniredja. 2010Model-Model Pembelajaran Inovatif dan Efektif.Bandung: ALFABETA. 